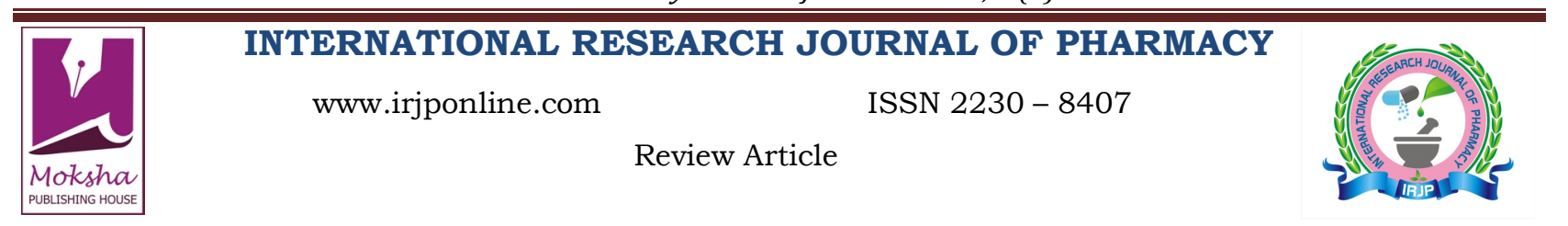

\title{
FEED FORMULATION AND FEEDING TECHNOLOGY FOR FISHES
}

Govind Pandey*

Professor/Principal Scientist and In-Charge, Department of Pharmacology \& Toxicology, College of Veterinary Science \& Animal Husbandry, Rewa, The Nanaji Deshmukh Veterinary Science University (NDVSU), Jabalpur, MP, India E-mail: drgovindpandey@rediffmail.com

Article Received on: 10/01/13 Revised on: 01/02/13 Approved for publication: 01/03/13

DOI: $\mathbf{1 0 . 7 8 9 7 / 2 2 3 0 - 8 4 0 7 . 0 4 3 0 6}$

IRJP is an official publication of Moksha Publishing House. Website: www.mokshaph.com

(C) All rights reserved.

\section{ABSTRACT}

Most fish farmers and ornamental fish hobbyists buy the bulk of their feed from commercial manufacturers. However, small quantities of specialized feeds are often needed for experimental purposes, feeding difficult-to maintain aquarium fishes, larval or small juvenile fishes, brood fish conditioning, or administering medication to sick fish. Small ornamental fish farms with an assortment of fish require small amounts of various diets with particular ingredients. It is not cost effective for commercial manufacturers to produce very small quantities of specialized feeds. Most feed mills will only produce custom formulations in quantities of more than one ton, and medicated feeds are usually sold in 50-pound bags. Small fish farmers, hobbyists and laboratory technicians are, therefore, left with the option of buying large quantities of expensive feed, which often goes to waste. Small quantities of fish feeds can be made quite easily in the laboratory, classroom, or at home, with common ingredients and simple kitchen or laboratory equipment. Hence, this review provides the knowledge about the fish feed formulation and feeding technology concerned with the live feed for fish larvae, fish feeds, fish feed ingredients, common fish feed stuffs, animal and plant sources of feeds for culture fish, and fish feeding methods.

Keywords: Carbohydrates, essential amino acids (EAAs), fats/lipids, feed formulations, fish feeds/fish meals, fish, minerals, vitamins.

\section{INTRODUCTION}

EAAs can not be synthesized by fish and often remain inadequate but are needed for growth and tissue development ${ }^{1-2}$. 'Fish meal' is known to contain complete EAAs profile that is needed to meet the protein requirement of most fish species. Since fish meal is expensive as a feed ingredient, the use of nonconventional feed stuffs has been reported with good growth and better cost benefit values. The utilization of nonconventional feed stuffs of plant origin had been limited as a result of the presence of alkaloids, glycosides, oxalic acids, phytates, protease inhibitors, haematoglutinin, saponegin, momosine, cyanoglycosides and linamarin to mention a few despite their nutrient values and low cost implications ${ }^{3}$. 'Nonconventional feed resources' (NCFRs) are feeds that are not usually common in the markets, and are not the traditional ingredients used for commercial fish feed production ${ }^{4-5}$. NCFRs are noncompetitive in terms of human consumption, very cheap to purchase, byproducts or waste products from agriculture, farm made feeds and processing industries, and are able to serve as a form of waste management in enhancing good sanitation. These include all types of feed stuffs from animals (silkworm, maggot, termite, grub, earthworm, snail, tadpoles, etc.), plant wastes (jack bean, cottonseed meal, soybean meal, cajanus, chaya, duckweed, maize bran, rice bran, palm kernel cake, groundnut cake, brewers waste, etc.), and wastes from animal sources and processing of food for human consumption like animal dung, offal, visceral, feathers, fish silage, bone, blood $)^{4}$. All these can be recycled to improve their value if there are economically justifiable and technological means for converting them into usable products. The basic nutrient which can not be compromised in the choice of ingredients for feed formulation and preparation is protein $^{6}$.

Advances in life support technology have been substantial in recent years, and nutrition is increasingly regarded a key limitation to increased production efficiency as well as the growth and propagation of 'new' species. Commercially prepared diets for channel catfish and salmonids have been developed using a great deal of research data on specific nutritional requirements of these species, their production systems and their life stages. Some nutritional studies have also been carried out for tilapia production. For all other species, including freshwater and marine ornamentals, nutritional management is based on a combination of application of knowledge generated for the species mentioned above and the experience of successful aquarists ${ }^{7}$. Most successfully reared ornamental fish are omnivores, and these are the species that have adapted best to captive conditions, including available nutrition. Successful maintenance of 'difficult' species is often influenced by the aquarist's success in obtaining or rearing specialized food items. For example, members of the highly popular sygnathid family, sea horses and sea dragons, have long, tubular mouth parts. These fish are not physically capable of ingesting typical commercial fish foods. Instead, successful husbandry typically involves significant investment in the rearing of brine or mycid shrimp. The popularity of these fish has made the extra investment worthwhile for many commercial exhibits, but makes it unrealistic for the typical home aquarist $^{8}$.

Usually, feeds for fry and fingerlings frequently exceed $50 \%$ crude protein. As growth rate decreases with fish age, the protein levels in diets are decreased accordingly. Protein levels on grow out diets often approach or exceed $40 \%$ crude protein, while maintenance diets may contain as little as 25 $35 \%$. In addition to decreasing the protein content of the food as fish grow, the particle size must also be changed. Many fish require live food when they are hatched because their mouth parts are so small. Some fish, such as the channel catfish, are large enough to place on a fry diet immediately without having to bother with the expense and labour needed for live foods?.

Fish meal should be a major protein source in fish diets. There are essential amino and fatty acids that are present in fish meal but not present in tissue from terrestrial plants or 
animals. Low cost formulations in which fish meal has been eliminated and replaced by less expensive proteins from terrestrial sources (soybeans) are not recommended for fish. Fish meals and fishery byproducts have high lipid content and therefore rancidity can be a problem if foods are not properly stored. In addition to the concern for EAAs that may be present in fish meals, fish require long chain fatty acids (C20 and C22) that are not found in tissue from terrestrial organisms. Fish meals, shrimp meals and various types of fishery byproducts are the source for these EAAs. In addition, crustacean byproducts serve as a source of carotenoid pigments that are excellent for colour enhancement. There is a high oil content associated with carotenoid pigments, so vitamin E supplementation is recommended when these are used $^{1,10}$. It is known that fish absorb minerals from the water. Calcium deficiency of channel catfish fry has been associated with calcium concentrations less than $10 \mathrm{mg} / \mathrm{L}$ in rearing systems. Calcium chloride has been used to raise the calcium concentration of water used for fry rearing. Conversely, too much calcium in the water has been associated with reproductive problems in some fish. Water hardness $>100$ $\mathrm{mg} / \mathrm{L}$ has been attributed to formation of hard shells for eggs of some tetra species, and fry were not able to hatch ${ }^{11}$. Most fish require dietary ascorbic acid (vitamin C). Ascorbic acid added to fish feeds should be phoshorylated to stabilize the vitamin and increase storage time. In addition, vitamins A, D, $\mathrm{E}$ and $\mathrm{B}$ complex should be added to fish foods. The concentration of vitamin $\mathrm{E}$ is often inadequate, especially in diets which are high in fat. If fish are housed in natural systems with algae and phytoplankton, and stocking rates are not too great, then vitamin supplementation seems to be less important, presumably because of the availability of natural food items ${ }^{1,12}$.

Because fish feeds usually contain relatively high amounts of fish meal and/or fish oil, they are very susceptible to rancidity. In addition, ascorbic acid is highly volatile, but critical to normal growth and development of most species of fish. For these reasons, fish feeds should be purchased frequently, ideally at least once a month and more frequently if possible. Feeds should be stored in a cool, dry place and should never be kept on hand for more than three months. Refrigeration of dry feeds is not recommended because of the high moisture content of that environment. Freezing is an acceptable way of extending the shelf life, however ${ }^{13}$. Stabilized (phosphorylated) forms of ascorbic acid are available and are used in many, but not all, fish feeds. Feeds that do not contain stabilized ascorbic acid are not recommended for fish. Commercially milled fish foods are usually sold as dry or semi-moist pellets or as flakes. Pellets are typically the most complete diets. They are cooked, and, if marketed as a complete ration, the nutrition in each particle should be uniform. Disadvantages include the potential for rapid sinking unless the pellet is extruded. In addition, the pellet size is very important. It may be impossible to manufacture a particle small enough for some fish, especially juveniles of many species. For larger animals, a very small pellet may be unacceptable. Semi-moist diets are soft and compact. Many of these are expensive, but they tend to be high quality diets and may be an excellent choice for some species $^{14}$. Flakes have been used extensively in the ornamental fish industry for many years and have the advantage of being soft enough for very small fish to consume. They also sink very slowly ${ }^{13}$.

Technology associated with rearing of live foods is improving rapidly. This is having a positive impact on larval rearing, a frequent bottleneck for commercialization of 'new' species. Rotifers are the smallest live food that is routinely used for larval rearing. Newly hatched brine shrimp are larger, but still quite small, and are commonly used in fish hatcheries. Cultured live foods can provide a source of high quality nutrition, but care must be taken to avoid perpetuation of infectious disease. Use of wild caught food items is also risky because of the potential for disease introduction ${ }^{12}$. Fish should be fed based on a percentage of body weight. For maintenance, $51.0 \%$ body weight per day is adequate. Fish should probably be fed at least 5 days per week. The most common mistake made by pet owners is overfeeding their fish, often with resulting degradation of water quality. Occasionally, the owners underfeed their fish. One feeding per day is plenty for most pet animals. Rearing of young stock does require small meals fed more frequently. This is often accomplished using automatic feeders on commercial farms ${ }^{10}$.

Advances in the diagnosis and correction of nutritional disease should be significant over the next few years as there seems to be a great deal of research activity in this area. In the interim, practitioners are encouraged to include questions about diet and feeding practices in their histories and to keep the potential for a nutritional aetiology in mind when working through perplexing cases $^{1,7}$.

\section{Feed for Fish Larvae}

'Live feed' during the first few days of hatching is necessary to ensure adequate larva survival. Fish larvae fed with live feed in the wild or cultured have higher survival rate than those fed with dry artificial feeds ${ }^{8}$. Live feed organisms include zooplanktons. These are the rotifers, copepods, cladoceras and other larval and adult forms of some invertebrates. The type of fish feed determines fish production ${ }^{9}$. Successful rearing of milkfish (Chanos chanos) larvae also depends almost entirely on the use of the live feed, rotifer (Branchinous plicatilus). The most widely cultured feed are rotifers because of their abundance in any water body. Monia and Daphnia species are also widely cultured $^{10}$.

Live feeds can be cultured using both organic and inorganic fertilizers. These fertilize the medium to produce a phytoplankton bloom. The desired species of zooplankton for the culture are later introduced into the medium. The use of inorganic fertilizer (NPK and urea mixture) can be effective for the culture of Moina sp. A shed of $3 \mathrm{~m} \times 4 \mathrm{~m}$ constructed and plastic bowels of $40 \mathrm{~L}$ capacity is preferable for the culture. Different mixtures can be used. Moina species seem to grow best in $0.5 \mathrm{~g}$ urea and $0.5 \mathrm{~g} \mathrm{NPK}$ and increases in growth rate within few days of inoculation ${ }^{11}$. Live feeds can also be cultured using concrete tanks covered with transparent nylon sheets. The nylon sheet allows light to pass through the concrete tank. The water can be fertilized with chicken manure or cow dung mixture. The ratio of 31:7 of chicken manure and cow dung is recommended. Algal bloom appears after fertilization, followed by zooplankton, in most cases, the rotifer Asplanchna priodonta appears after the inoculation. An abundance of 100,000 organisms per liter can be observed at the peak of the bloom ${ }^{12}$.

The best method of culturing live feed is the use of earthen ponds fertilized with chicken manure. The reason is that, it saves cost. Spread manure on dry grass (hay) and immediately fertilize with chicken manure. Pump the water into the pond. Zooplanktons such as Moina species and the rotifer, Branchiones species will appear after a few days of 
fertilization. This method of culture multiplies zooplankton quickly, because earthen ponds are natural habitats of zooplanktons. The water that is pumped may contain live organisms with eggs in sale. Fertilization of the pond also adds enough nutrient requirements. This enhances plankton growth within the shortest possible time. In earthen ponds, dykes of the pond create lacustine conditions and these conditions favour zooplankton growth ${ }^{1,13}$.

\section{Fish Feed Ingredients/Nutrients}

Many fish farmers and ornamental fish hobbyists buy the bulk of their feed made commercially. However, small quantities of specialized feeds are often needed for experimental purposes, feeding difficult-to maintain aquarium fishes, larval or small juvenile fishes, brood fish conditioning, or administering medication to sick fish. Small ornamental fish farms with an assortment of fish require small amounts of various diets with particular ingredients. It is not cost effective for commercial manufacturers to produce very small quantities of specialized feeds. Most feed mills will only produce custom formulations of more than one ton, and medicated feeds are usually sold in 50-pound bags. Small fish farmers, hobbyists and laboratory technicians are, therefore, left with the option of buying large quantities of expensive feed, which often goes to waste. Small quantities of fish feeds can be made quite easily in the laboratory, classroom, or at home, with common ingredients and simple kitchen or laboratory equipment. Nutrients essential to fish are the same as those required by most other animals ${ }^{1,15-16}$.

In their natural environment, fish have developed a wide variety of feeding specializations (behavioural, morphological and physiological) to acquire essential nutrients and utilize varied food sources. Based on their primary diet, fish are classified as: carnivorous (consuming largely animal material), herbivorous (consuming primarily plant and algae), or omnivorous (having a diet based on both plant and animal materials). However, regardless of their feeding classification, in captivity fish can be taught to readily accept various prepared foods which contain the necessary nutrients ${ }^{1,15}$.

The nutrients essential to fish are the same as those required by most other animals. These include water, proteins (amino acids), lipids (fats, oils, fatty acids), carbohydrates (sugars, starch), vitamins and minerals. In addition, pigments (carotenoids) are commonly added to the diet of salmonid and 'ornamental aquarium' fishes to enhance their flesh and skin coloration, respectively. These fish feed ingredients/nutrients have been described ${ }^{1,15-16}$ as below:

Proteins and amino acids: Fish meal, soybean meal, fish hydrosylate, skim milk powder, legumes, and wheat gluten are excellent sources of protein. Additionally, the building blocks of proteins (free amino acids) such as lysine and methionine are commercially available to supplement the diet. Utilizing raw fish as a main ingredient in fish feeds has long been recognized to be harmful to the health and growth of fish due primarily to the presence of the anti-nutrient, thiaminase. Thiaminase, an enzyme that destroys thiamine (vitamin $\mathrm{B} 1$, one of the essential water soluble vitamins), is mostly found in freshwater fish. It is destroyed by the heat (i.e., cooking). Other concerns related to using raw fish in diets include the spread of infectious diseases such as Mycobacterium and botulism. In preparing diets, preferential use of marine fish is suggested to minimize thiaminase activity, and the raw fish could be steamed or poached.
Lipids: Oils from marine fish, such as menhaden, and vegetable oils from canola, sunflower and linseed, are common sources of lipids in fish feeds.

Carbohydrates: Cooked carbohydrates from flours of corn, wheat or other 'breakfast' cereals, are relatively inexpensive sources of energy that may spare protein (which is more expensive) from being used as an energy source.

Vitamins and minerals: The variety and amount of vitamins and minerals are so complex that they are usually prepared synthetically and are available commercially as a balanced and premeasured mixture known as a vitamin or mineral premix. This premix is added to the diet in generous amounts to ensure that adequate levels of vitamins and minerals are supplied to meet dietary requirements.

Pigments: A variety of natural and synthetic pigments or carotenoids are available to enhance coloration in the flesh of salmonid fish and the skin of fresh water and marine ornamental fish. The pigments most frequently used supply the colours red and yellow. The synthetically produced pigment, astaxanthin, is the most commonly used additive $(100-400 \mathrm{mg} / \mathrm{kg}$ ). Cyanobacteria (bluegreen algae such as Spirulina), dried shrimp meal, shrimp and palm oils, and extracts from marigold, red peppers and Phaffia yeast are excellent natural sources of pigments.

Binding agents: Another important ingredient in fish diets is a binding agent to provide stability to the pellet and reduce leaching of nutrients into the water. Beef heart has traditionally been used both as a source of protein, and as an effective binder in farm made feeds. Carbohydrates (starch, cellulose, pectin), and various other polysaccharides, such as extracts or derivatives from animals (gelatin), plants (gum arabic, locust bean) and sea weeds (agar, carageenin and other alginates) are also popular binding agents.

Preservatives: Preservatives, such as antimicrobials and antioxidants are often added to extend the shelf life of fish diets and reduce the rancidity of the fats. Vitamin $\mathrm{E}$ is an effective, but expensive, antioxidant that can be used in laboratory prepared formulations. Commonly available commercial antioxidants are butylated hydroxyanisole (BHA), or butylated hydroxytoluene (BHT) and ethoxyquin. BHA and BHT are added at $0.005 \%$ of dry weight of the diet or no more than $0.02 \%$ of the fat content in the diet, while ethoxyquin is added at $150 \mathrm{mg} / \mathrm{kg}$ of the diet. Sodium and potassium salts of propionic, benzoic or sorbic acids are commonly available antimicrobials added at less than $0.1 \%$ in the manufacture of fish feeds.

Attractants: Other common additives incorporated into fish feeds are chemo-attractants and flavorings, such as fish hydrosylates and condensed fish solubles (typically added at $5 \%$ of the diet). The amino acids glycine and alanine, and the chemical betaine are also known to stimulate strong feeding behavior in fish. Basically, the attractants enhance feed palatability and its intake.

Other feedstuffs: Fiber and ash (minerals) are a group of mixed materials found in most feed stuffs. In experimental diets, fiber is used as a filler, and ash as a source of calcium and phosphorus. In practical diets, both should be no higher than $8-12 \%$ of the formulation. A high fiber and ash content 
reduces the digestibility of other ingredients in the diet resulting in poor growth of the fish. Other common feed stuffs used in ornamental fish diets include live, frozen or dried algae, brine shrimp, rotifers or other zooplankton. Addition of fish or squid meal will enhance the nutritional value of the diet and increase its acceptance by the fish. Fresh leafy or cooked green vegetables are often used. Although vegetables are composed mainly of water, they contain some ash, carbohydrates and certain vitamins. Kale, dandelion greens, parsley and turnip greens are examples of relatively nutritious vegetables. The quality and form of feed required depends on the nutritional needs, feeding habit and age of fish. Many domestic and agricultural wastes such as corn bran, guinea corn bran, rice bran, wheat bran, brewery wastes, blood meal, fish meal, palm kernel cake, groundnut cake, cotton seed cake, soybean, vegetable oil, palm oil etc. are some main ingredients required for compounding artificial fish diet to reduce the cost of producing a fish. Fish feeds are the fine particles of ground feed stuffs given to fish in small compact, cylindrical and head like forms called 'pellets'. The pellets could be moist, dry or extruded dry with natural material such as spleen, ground liver, heart and raw fish. Moist pellet contaminates the water causing pollution and contains $25-35 \%$ water. Except the diet is pasteurized, there is the possibility of introducing pathogens into the fish. Inadequate transport and storage destroy certain vitamins and lipids. The handling of this type of feed can be difficult and expensive. However, moist fish feed are readily digestible by fry and fingerlings. They also have the desirable floating qualities, water stability, and the feed can easily be observed on introduction. Dry fish feeds are more popular because they are easier to manufacture, transport and store. Their nature reduces leeching of nutrients. However, dry fish feeds are not easily observed on introduction. Overheating can occur during manufacture.

The general proportions of various nutrients included in a standard fish diet ${ }^{15-16}$ are given in Table 1.

Table 1: General amounts of nutrients incorporated into diets for growing fish

\begin{tabular}{|c|c|}
\hline Nutrients & Requirement (\% by dry diet) \\
\hline $\begin{array}{l}\text { Proteins: These include } 10 \text { essential amino acids, viz., lysine, phenylalanine, arginine, valine, leucine, } \\
\text { isoleucine, methionine, threonine, tryptophan and histidine. }\end{array}$ & $32-45 \%$ \\
\hline $\begin{array}{l}\text { Fat: Used as a source of energy and polyunsaturated fatty acids. Generally, freshwater fish require } \\
\text { fatty acids of the linolenic (w-3) and linoleic (w-6) series; while saltwater and coldwater fish require } \\
\text { EPA and DHA (w-3). }\end{array}$ & $\begin{array}{c}4-28 \% \text { (should contain at least } 1-2 \% \text { of the w-6 } \\
\text { or w-3 essential fatty acid series) }\end{array}$ \\
\hline $\begin{array}{l}\text { Carbohydrates: These are an inexpensive source of energy and are binding agents. No essential } \\
\text { requirements have been identified. These are poorly digested when fed raw; highest digestibility is } \\
\text { achieved when cooked. Major carbohydrates are starch, cellulose and pectin. }\end{array}$ & $10-30 \%$ \\
\hline $\begin{array}{l}\text { Vitamins: These are inorganic substances required in trace amounts that can be divided into fat- } \\
\text { soluble (vitamins A, D, E and K) and water-soluble (vitamin B-complex, viz., thiamine, riboflavin, } \\
\text { pyridoxine, pantothenic acid, cyanocobalamin, niacin, biotin, folic acid choline and myoinositol; and } \\
\text { vitamin C). }\end{array}$ & $\begin{array}{l}1.0-2.5 \% \text { (fed primarily as a multi-vitamin } \\
\text { premix; vitamin choline and } \mathrm{C} \text { are added } \\
\text { separately from the premix because of their } \\
\text { chemical instability) }\end{array}$ \\
\hline
\end{tabular}

\section{Some Common Conventional Feedstuffs}

Some common conventional feedstuffs are as under ${ }^{1}$ :

Groundnut cake: This contains about $45 \%$ crude protein but lacks the essential amino acid, lysine. When moldy, it becomes poisonous due to the presence of mycotoxin called 'aflatoxin'.

Soybean meal: This feedstuff is fast gaining increasing acceptability. It has a balanced amino acid profile and can replace a substantial part of fish meal. The use of this feedstuff is, however, limited due to its high fat content and presence of trypsin inhibitor.

Palm kernel meal: This contains a fairly high quantity of crude fiber. The crude protein is $17 \%$. Palm kernel meals are only useful when its crude fiber content is high.

Brewers dried yeast: This is a byproduct of the brewery industry. It contains sufficient quantity of crude protein but limited in amino acids methionine and cystine.

Brewers dried grain: This is readily available and contains similar protein levels as palm kernel cake. The crude fiber content is high and so, this is in limited use.
Maize: It is palatable and free from anti-nutritional factors. Its energy content is high. This limits the use in fish feed.

Wheat offal: The nutritional property of wheat offal is similar to palm kernel meals. The two can therefore be used interchangeably but scarcely together. Wheat offal is very scarce due to adverse government policy.

Fish meal: Fish feed is hardly formulated without fish meal. Apart from its high protein content, fish meal also acts as an attractant. Fish meal is produced either from the trash obtained from trawling or fish waste from the canning industry. The percentage protein depends on the source of fish product and method used in producing the fish meal.

Poultry byproduct meal: Poultry processing generates a lot of wastes such as offal, blood and heads of birds. These wastes can be processed to form poultry byproduct meal. The protein content is high with a balanced amino acid profile. It can replace fish meal without any adverse effect on the fish. Some conventional types of fish meals (fish feedstuffs), with their maximum and minimum levels ${ }^{1,11}$ are shown in Table 2. 


\begin{tabular}{|c|c|c|}
\hline Type of fish meal & Maximum level (\%) & Minimum level (\%) \\
\hline Fish meal (tuna waste, 56\% protein) & 50 & 10 \\
\hline Fish meal (miscellaneous, 60\% protein) & 50 & - \\
\hline Poultry byproduct meal (58\% protein) & 10 & 2 \\
\hline Fish protein concentrate (soluble, 70\% protein) & 5 & - \\
\hline Blood meal (80\% protein) & 3 & - \\
\hline Soybean meal (38\% protein) & 30 & - \\
\hline Soybean meal (solvent extract, 48\% protein) & 45 & - \\
\hline Groundnut cake meat (45\% protein) & 5 & 2 \\
\hline Brewers dried yeast (30\% protein) & 5 & - \\
\hline Brewers dried grains (18\% protein) & 5 & - \\
\hline Palm kernel cake meal (18\% protein) & 5 & - \\
\hline Wheat middling (17\% protein) & 5 & - \\
\hline Rice brans (12\% protein) & 3 & 5 \\
\hline Maize (10\% protein) & 20 & 3 \\
\hline Sorghum (guinea corn, $10 \%$ protein) & 10 & \\
\hline
\end{tabular}

\section{Unconventional Feeds for Culture Fish}

'Unconventional fish feeds' are potential feed ingredients, which have hitherto not been used in fish feed production for the reasons that: they are not well known or understood; there is no effective study of the method of production with a view to commercializing them; they are not readily available; and they can be toxic or poisonous. These feeds are generally referred to as 'unconventional feed ingredients'. They contain high quality feed ingredients that can compare favourably with conventional feed types. They are expected to be cheaper by virtue of the fact that there is no competition for human consumption. The unconventional fish feed can be of 'animal' or 'plant' source which have been described below':

1. Animal source: These are feed from any living thing, other than human being, that can feel and move, e.g., tadpole meal, fly larvae, earthworm meal, toad meal, shrimp waste, crab meal, and animal wastes such as pig and poultry droppings and blood meal.

(a) Tadpole meal- Frogs and toads breed at the onset of rainy season with the first rains acting as stimulus for reproduction. Eggs are laid in stagnant pools or any body of water and later hatch into tadpoles. The tadpoles are seen swimming and feeding from food obtained in the pool of water. These tadpoles survive until the pool either dries up, or they metamorphose into adult frogs or toads in 23 months. Because of the period of life cycle spent in water, the tadpoles can be cultured like fish and harvested before they can metamorphose. The harvested tadpoles can be processed by oven drying or smoking over a kiln. For immediate use, they can be fed whole to adult fish or pulverized and added to other feed ingredients at $40-50 \%$ depending on availability. This meal contains about $50 \%$ crude protein. It can be used in place of fish meal.

(b) House fly larvae (Musia domestica)- When there is a supply of damp decaying organic matter, the house flies thrive. It serves both as food and breeding ground for the adults and sustenance for the resultant larvae. In fact, within a short period of the existence of such matter, the large number of fly eggs became apparent. A simulation of such condition is achieved by creating a decaying organic matter with an attractant such as a combination of fish on trays or shrimp waste with finely ground maize or soybeans, groundnut cake or palm kernel cake. The mixture is turned into a slummy watery waste with water in a drum one quarter or half filled and left open in the field. Harvesting of maggots can commence from the third day. When the quantity of wriggling larvae (maggots) is satisfactorily high, the paste is diluted and larvae are harvested with a fine mesh sieve, washed thoroughly to remove the substrate and allowed to drip dry. Processed larvae can contain $8 \%$ moisture, $45 \%$ protein, $15 \%$ fat, $8 \%$ ash and $25 \%$ chitin.

(c) Animal wastes- Faeces from animals, particularly piggery and poultry droppings, can be used as pond organic fertilizers for the stimulation of plankton growth. However, both animal droppings are used as a direct source of food to fish. As direct food for fish, pig wastes collected early in the morning without contamination by pig urine are dropped into a marked area of the pond as food. The same thing goes for poultry droppings. In fact, some fish culturist use poultry droppings without further use of any artificial feed with good results. However, care must be taken to avoid pond contamination. As after fermentation and build up of fly larvae, the droppings can be left in open containers for a few days to allow fermentation and build up of larvae. The larvae and droppings are let into the ponds. As oven drying and incorporation into feeds, the dropping can be oven dried or sun dried during the harmattan period and added to other ingredients in fish feed. Such droppings contain about $30 \%$ crude protein content. The animal wastes are especially useful in the polyculture of local catfishes and tilapias.

(d) Earthworm meal (Lumbricus terrestris and Allobophora long): These are detritivorous terrestrial oligocheate worms. They live in the soil and feed on decaying leaves and other organic matter, which they later pass out as worm caste. In other words, they convert organic matter to soil. So, they are used in the breakdown and utilization of human and animal waste. These worms are hermaphrodites and reproduce while being used to break down detritus increasing their number at the same time. They are commercially produced by heaping animal, human wastes or refuge in a land with enough moisture in the soil or swamps. Suitable pairs of earthworms are introduced. These would breed with the detritus serving as source of nutrients to them. Harvesting can be done after six months. This is by digging up lumps of earth and gently breaking them up to release the worms. Processing is either by oven drying, smoking over a kiln or pulversing with a pepper grinder.

(e) Toad meal (Bufo regularis)- Toads in the tropics are seen in moist or damp areas in the forests, house surroundings, etc. In dry season, they move under stones. They breed by laying large number of eggs in pools of water during the rains, which hatch into tadpoles. The tadpoles 
metamorphose into toads. Thus, it is possible to breed toads on a commercial scale and processed by oven drying. Toads are however, viewed with revulsion and people seldom touch it because of its moist rough skin. Some fish culturists kill toads and put into the fish pond. When the toads go putrid, the catfishes feed on it. Putrefaction or fermentation removes the poison in the toad skin. The toads contain $99 \%$ protein and compares favourably with fish meal.

(f) Blood meal- Cow blood is daily available in the slaughter houses. Processing is, by boiling the blood followed by dry in an oven or smoke; sun dry, particularly during the harmattan (bulk of commercial blood meal is processed during the dry season); and added straight into the mixture of well ground ingredients. Dry cassava powder can be used as a binder and boiling water to gelatinize it. Mix thoroughly and spread out to dry. The result is a feed with crumble consistency ideal for adult fish and fingerlings. Blood meal is high in protein content $(85 \%)$. It is a supplemental source of lysine but low in methionine. Antagonism exists between leucine and isoleucine which renders the latter unavailable if combined with soybean meal, which is an ideal for fish growth.

2. Plant sources: The plant sources of fish diets include: leaf protein, leaf meal, aquatic macrophytes, cultivable pulses such as mucuna bean, yam beans, bread beans, winged beans or any legume ornamental that can yield pods with seeds.

(a) Leaf protein- Leaves are abounding in the tropics growing freely without cultivation. All contain diverse levels of protein, which can produce an inexhaustible and inexpensive source of nutrient for fish. Nutritionally valued leaves are cassava (Manihot. esculenta), pawpaw (Carica. papaya), pineapple (Ananas. comosus), Groundnut (Arachis hypogea), soya bean/soybean (Glycine max) and plantain (Musa paradisica). A number of techniques have been evolved for extracting protein from leaves. The crushing of leaves into a solution with trichloroacetic acid is a useful method. The mixture is allowed to settle in separating flax for a period of $12 \mathrm{hr}$. The bottom slurry is protein obtained by decanting and drying. Any leave is suitable for this method. The resulting powder is leaf protein concentrate containing up to $15-50 \%$ crude protein.

(b) Aquatic macrophytes- These are common aquatic plants found growing on water surface. These include: rooted flowering plants like grasses and sedges that are commonly seen along the rim of fresh water bodies; rotted flowering plants with submerged leaves like ceratophyllum, and with floating leaves like water lilies (nymphaea); free floating plants such as duckweed, water lettuce, water hyacinth and salvinia, a water fern. Water hyacinth are so wide spread that they constitute a menace to shipping and fishing activities but can be used as feed component for fish. A review of studies carried out on Azolla piñnata and Eichhornia crassipes are as follows:

(c) Azolla piñnata (fresh water fern): This is a potential fish feed component in the diet of Oreochromis niloticus. Its oven dried state is equated with palm kernel cake. Forty percent of A. piñnata can be used in tilapia diets. The plant grows fast, so can readily meet the needs. The oven dried sample contains $27 \%$ crude protein. (d) Eichhornia crassipes (Water hyacinth): It can be used in the diet of $C$. nigrodigitatus and other cultivable fish species, e.g., C. niloticus, Heterotis niloticus, etc. The plant grows very fast and abounds for commercial usage. Processing can be done by oven drying and protein extraction as in leaf protein.

(e) Unconventional pulses- A rang of legumes are used as cover crops or ornamentals. They are not eaten by reasons of suspected content of toxic substances. For example, mucuna beans, broad beans, sword beans, winged beans, yam beans, etc. Their protein contents range from $18-20 \%$, fat $3-10 \%$ and carbohydrate $50-60 \%$, making them easily gelatinisable. Toxic substances in them are hydrogen cyanide and trypsin inhibitors. These can be removed by applying heat during processing, which can be done by toasting (groundnut fashion), boiling, steam cooking or drying.

\section{Preparation of Fish Feed Formulations}

The feeds are formulated may be dry with a final moisture content of $6-10 \%$; semi-moist with $35-40 \%$ water; or wet with $50-70 \%$ water content. The most feeds used in intensive production systems or in home aquaria are commercially produced as dry feeds. The dry feeds may consist of simple loose mixtures of dry ingredients, such as mash or meals, to more complex compressed pellets or granules. Pellets are often broken into smaller sizes known as 'crumbles'. The pellets or granules can be made by cooking with steam or by extrusion. Depending on the feeding requirements of fish, the pellets can be made to sink or float ${ }^{1,15}$.

Flakes are another form of dry food and a popular diet for aquarium fishes. The flakes consist of a complex mixture of ingredients, including pigments. These are made into slurry which is cooked and rolled over drums heated by steam. Semi-moist and wet feeds are made from single or mixed ingredients, such as trash fish or cooked legumes, and can be shaped into cakes or balls.

There is no single way for preparation of formulated fish feed; however, most methods begin with the formation of a dough like mixture of ingredients. The ingredients can be obtained from feed stores, grocery stores, pharmacies and specialty stores such as natural food stores, as well as from various companies that may be found through the internet. Dough is started with blends of dry ingredients which are finely ground and mixed. The dough is then kneaded and water is added to produce desired consistency for whatever fish is going to be fed. The same dough may be used to feed several types of fish, such as eels and small aquarium fish. Pelleting or rolling converts the dough into pellets or flakes, respectively. The amount of water, pressure, friction and heat greatly affects pellet and flake quality. For instance, excess water in the mixture results in a soft pellet. Too little moisture and pellet will crumble. Proteins and especially vitamins are seriously affected by high temperatures. Thus, avoid storing diet ingredients at temperatures at or above $70^{\circ} \mathrm{C}$ and do not prepare dry feeds with water at temperature higher than $92^{\circ} \mathrm{C}^{1,15}$.

To make the own fish feed, few specialized tools are required. The tools are used primarily for chopping, weighing, measuring ingredients, and for blending, forming and drying the feed. Most of the utensils needed are already available in the laboratory or kitchen. The multipurpose kitchen shears, hand graters, a paring knife, a 5 inches serrated knife, a 6 to 8 inches narrow blade utility knife and a 10 inches chef knife for cutting, slicing and peeling can be 
used. A couple of plastic cutting boards protect the counter and facilitate the handling of raw ingredients. Heat resistant rubber spatulas, wooden and slotted spoons, long handled forks and tongs are very good for handling and mixing ingredients. A basic mortar and pestle, electric blender, food processor or coffee grinder are very useful to chop or puree ingredients. A food mill and strainer such as a colander or flour sifter help discard coarse material and obtain fine food particles. For weighing and measuring ingredients, dry and liquid measuring cups and spoons, and a food or laboratory bench scale are required. Other utensils include plastic bowls $\left(1 \frac{1}{2}, 3,5\right.$, and 8 quarts) for weighing and mixing ingredients, a thermometer and a timer. A 3-quart saucepan and 10 inches stockpot are good for heating gelatins and cooking raw foods like vegetables and starches. The ingredients and blends may be cooked in a small electric or gas burner. A few trivets to put under hot pans will protect counters and table tops. Ingredients may be mixed by hand using a rotary beater or wire whisk; however, an electric mixer or food processor is more efficient. After mixing, a dough is formed which can be fashioned into different shapes. A pasta maker, food or meat grinder will extrude the dough into noodles or 'spaghetti' of different diameters. As the noodles emerge from the outside surface of the die, they can be cut off with a knife to the desired length or crumbled by hand, thus making pellets. A potato ricer also serves to extrude the dough into noodles of the same size. For making flakes, a traditional handcranked or electric pasta maker will press out the dough into thin sheets. The pellets or thin sheets can be placed on a cookie sheet and dried in a household oven on low heat or in a forcedair oven. A small food dehydrator also performs the task quite well. To add extra oil and/or pigments to pellets, a handheld oil atomizer or sprayer can is useful. To separate pellets into different sizes, a set of sieves (e.g., 0.5, 0.8, 1.0, 2.0 and $3.0 \mathrm{~mm}$ ) is required ${ }^{1,15}$.

The freezer bags serve to store the prepared feeds, and using a bag vacuum sealer will greatly extend the shelf life of both ingredients and the feed. The feed can be stored double bagged in the freezer but should be discarded after 6 months. Ideally, dried larval feeds are not frozen but stored in the refrigerator for no longer than 3 months. A finished diet, especially used for experimental purposes, should be analyzed for nutrient content (proximate analysis: crude protein, energy, moisture, etc.). Besides, any one intending to make his/her own fish feeds with unfamiliar ingredients, should have them analyzed prior to their use. Purified and semi-purified diets are used primarily in experimental formulations to study the effects a nutrient, such as the amount or type of protein, may have on the health and growth of fish. One simple formulation, which is used traditionally to feed ornamental fish in ponds, consists of a mixture of $30 \%$ ground and processed oats or wheat and $50 \%$ of fish meal or pellets from a commercial manufacturer. By weight, about $23 \%$ of fish oil, and a $0.3 \%$ vitamin and a $1 \%$ mineral premix are added to the mixture. This mixture is blended with water and can be formed into dough balls of different sizes. A semipurified diet determines the optimum protein level required. This diet also can be used as a basis for feeding other types of ornamental fish in the laboratory. The cichlid feed recipe was derived principally from salmonid formulations and uses casein as the purified protein source. The ingredients in the recipe given under major nutrient categories may include as proteins, carbohydrates, lipids, vitamins and minerals. Pigments are added to enhance the coloration of ornamental fish. The gelatin based diets are popular in the aquarium fish industry and useful for preparing medicated feeds at home $\mathrm{e}^{1,15}$. Feeds are compounded by the use of the popular 'Pearson square method'. In this method: put the ingredients on the left side; put the required protein level at the center; subtract each quantity from the required feed weight that would give protein level; and substitute to get the answer. For example, by using two ingredients, viz., corn with $10 \%$ protein and shrimp with $45 \%$ protein, the protein level $30 \%$ can be achieved $^{1}$.

\section{Fish Feeding Technology}

The most common technique of providing feed for the culture fish is to fertilize the culture media with organic and inorganic fertilizers to stimulate the growth of phytoplankton and zooplanktons. Other invertebrates like water insects and their larva, benthic invertebrates, and detritus materials are also utilized as food for fish. In a polyculture system where different species of fish are grown together, the fry and fingerlings of herbivorous fish are preyed upon by carnivores. With increased growth rate of the stocked fish, the available natural foods in the pond become inadequate to support the fish population. So, there is need to supplement the natural food with artificial feeds for enhanced fish growth. The selection of fish for culture with supplementary diet depends on the crude protein requirement of the fish and the unit cost of the feed ingredient available in a given locality. This consideration is important because the fish feed accounts for $40-70 \%$ of operating cost of a fish farm with an intensive management system ${ }^{14}$.

The feeding is one of the most important aspects of the fish culture. The basic activities of the fish are: its growth, development and reproduction. All these take place at the expense of energy, which enters the fish in the form of its food. All the other energy processes within the fish also proceed at the expense of the food. The first stage in the life of a fish is completed at the expense of the food reserves, which it receives from the yolk in the egg. However, the fish can only live on its yolk for a comparatively short time, and after a short period of mixed feeding, it goes over completely to the consumption of external food. Fish differ greatly in the character of the food they consume. Both the size and the systematic position of the food organisms are extremely variable. The range of type of food consumed by fish is greater than for other groups of vertebrates. Different technical methods are used for in administering feed to culture fish. Liming and fertilization produce fish food organisms. These are the phytoplankton and zooplanktons. The pond water turns green when planktons are many. Supplementary feeds are given to fish in addition to the natural food organisms in the water body. Supplementary feeds contain all the essential nutrients, e.g., proteins, carbohydrates, lipids, vitamins and minerals required for fish growth. The supplementary feeds are introduced into the pond by broadcasting and spot feeding. In broadcasting, the feed is spread over the pond. Spreading is enhanced by drifting of the pond water. This method often contaminates the pond. Spot or spontaneous feeding involves placing the feed in a bag and tied on a spot. Alternatively, the feed is introduced at a particular time. The fish is fed $(34 \%$ body weight) twice daily, preferably morning and evening. The fish fry is fed with paste made from boiled chicken egg. Ideally, 25-30\% protein level is required for feeding fish in the pond ${ }^{17}$. 


\section{CONCLUSION}

Fish feeds, live feed for fish larvae, fish feed ingredients, some common conventional feedstuffs, animal and plant sources of unconventional feeds for culture fish, fish feed formulation, and feeding methods are important for the effective management of fish farming. Nutrients essential to fish are the same as those required by most other animals. These include water, proteins (amino acids), lipids (fats, oils, fatty acids), carbohydrates (sugars, starch), vitamins, minerals, pigments (carotenoids), etc.

\section{REFERENCES}

1. Abowei JFN, Ekubo AT. A review of conventional and unconventional feeds in fish nutrition. Br J Pharmacol Toxicol 2011; 2(4):179-191.

2. Wilson RP, Robinson EH, Gatlin DM, Poe WE. Dietary phosphorus requirement of channel catfish (Ictalurus punctatus). J. Nutr., 1989; 112(6):1197-1202.

3. Sogbesan, OA. Effects of different organic substrates on growth and survival of long winged termite (Macrotermes subhyabrius) under laboratory conditions. Afr J Gen Agric 2006; 2(2):37-44.

4. Devendra C. General approaches to animal nutrition research and their relevance to fish production in the Asian aegion. In: DeSilva SS, editor. Finfish Nutrition Research in Asia. Singapore: Heinemannn Asia Singapore; 1988 , p. 724.

5. Madu CT, Sogbesan OA, Ibiyo LMO. Some nonconventional fish feed resources in Nigeria. In: Eyo AA, editor. Proceeding of the Joint Fisheries Society of Nigeria held at National Institute for Freshwater Fisheries Research, New Bussa; 2003, p. 73-82.

6. Zeitler MH, Kirchgessner M, Schwarz EJ. Effects of different proteins and energy supplies on carcass composition of carp (Cyprinus carpio L.)
Aquaculture 1984; 36:37-48. http://dx.doi.org/10.1016/00448486(84)90052-8

7. Committee on Animal Nutrition (CAN). Nutrient requirements of Fish National Research Council. Washington DC: National Academy Press; 1993, p. 114.

8. Helfrich L, Smith S. Fish Kills: Their Causes and Prevention. Viginia; 2001.

9. Houlihan D, Bouiard T, Jobling M. Food intake in fish. Blackwell Sci. Ltd.: Iowa State University Press; 2001, p. 418.

10. Robert RS. Principles of Warm Water Aquaculture. New York: John Wiley and Sons; 1979, p. 375.

11. Roberts RJ. Nutritional pathology of teleosts. In: Fish Pathology. London: Balliere Tindall; 1989, p. 337-362.

12. Robinson E, Li M, Brunson M. Feeding catfish in commercial ponds. Southern Regional Aquaculture Center; http://www.msstate.edu/dept/sra c/fslist.htm; 1998.

13. Tom L, Van-Nostrand R. Nutrition and feeding of fish. New York; 1989 , p. 260.

14. Winfree RA. Nutrition and feeding of tropical fish. In: Gratzek JB, editor. The Science of Fish Health Management, Aquariology. NJ: Tetra Press, Morris Plains; 1992; p. 197-206.

15. Royes J-AB, Chapman FA. Preparing our own fish feeds. Institute of Food and Agricultural Sciences, University of Florida, Gainesville; 2009.

16. http://edis.ifas.ufl.edu.; 2009.

17. Lovell T. Nutrition and Feeding of Fish. New York: Van Nostrand Reinhold; 1988, p. 260.

Cite this article as:

Govind Pandey. Feed formulation and feeding technology for fishes. Int.

Res. J. Pharm. 2013; 4(3):23-30 